\title{
Dispositivo: Fusão de objeto e método de pesquisa em Michel Foucault
}

\author{
Device: fusion of object and research method on Michel Foucault
}

\author{
Cristian Caê Seemann Stassun ${ }^{1}$ \\ Selvino José Assmann²
}

\section{RESUMO}

Construir o caminho de acesso aos objetos de uma pesquisa gera a necessidade de regras e eixos centrais que ordenem de forma sistemática a forma de testar, observar, questionar ou investigar os objetos. Referente prática chamamos de método. Mais do que dispor como se faz isso de modo científico, acadêmico ou a partir de instrumentos de disciplinas, o modo de problematizar de Michel Foucault se mostrou arredio a definições e trajetórias normatizadas, práticas discursivas a quem por instituições, grupos de consensos e ordens produziam verdades fechadas e dispostas a emergir socialmente. Para tanto, a quem nega possuir uma metodologia, campo sistemático ou um roteiro pré-estabelecido, ele ofereceu em momentos pontuais ferramentas e alguns cuidados "metodológicos" essenciais. A conjuntura propiciada pela arqueologia e genealogia para analisar as vertentes do saber, poder e subjetividade apontaram para um vetor estratégico desses três focos de tensões, o conceito Dispositivo.

Palavras-chave: Dispositivo. Método. Foucault.

\section{ABSTRACT}

Building access path to the objects of a search generates the need for rules and central axis ordering in a systematic way how to test, observe, question and investigate the objects. Regarding practical method call. Have more than how to do it on a scientific, academic, or from instruments of disciplines, the way to discuss Michel Foucault proved elusive definitions and normalized trajectories, discursive practices to which institutions, groups and orders produced a consensus truths closed and socially ready to emerge. To do so, who denies having a methodology, systematic field or a pre-established, at times he offered some specific tools and care "methodological" key. The situation provided by the genealogy and archeology to examine the strands of knowledge, power and subjectivity pointed to an array of these three strategic foci of tension, the concept device.

Keywords: Device. Method. Foucault.

\footnotetext{
${ }^{1}$ Psicólogo, Especialista em Psicologia Clínica, Mestre em Psicologia, Doutorando Interdisciplinar em Ciências Humanas da UFSC. Email: cristianccss@hotmail.com.

${ }^{2}$ Doutor em Filosofia pela Pontificia Università Lateranense (1983), é professor titular da Universidade Federal de Santa Catarina, Membro de corpo editorial da Ethic@ - Revista Internacional de Filosofia da Moral e Membro de corpo editorial da INTERthesis (Florianópolis). selvinoa@terra.com.br
} 


\section{DISPOSITIVO: O VETOR DE CONCEITOS}

Proponho-Ihes nada menos que uma geral e maciça divisão do existente em dois grandes grupos ou classes: de um lado os seres viventes (ou as substâncias) e de outro os dispositivos nos quais estes estão incessantemente capturado (AGAMBEN, 2005a, p.1).

Seja em Foucault (1987), na descrição feita do Panóptico ${ }^{3}$ de Bentham (2000), das sociedades disciplinares como arquitetura de governo, ou em Deleuze (1992) pautando as sociedades de controle; o que está em jogo são formas de se exercer o poder, apoiadas em instrumentos de saber, produzindo efeitos de subjetivação e sujeição. Quando conseguimos isolar as estratégias destas relações de força que suportam tipos de saberes e vice-versa, podemos conceber, então, um dispositivo.

Agamben (2005) generaliza ${ }^{4}$ essa concepção e afirma que "[...] dir-se-ia que hoje não haveria um só instante na vida dos indivíduos que não seja modelado, contaminado ou controlado por algum dispositivo" (p.13). Prado Filho (2007) complementa que esse é um caminho de deslocamento da análise política, dos domínios do Estado para a sociedade, tal qual o resultado final de uma rede microfísica de poder de organizações, instituições, multiplicidade de relações, pequenas coerções e diversas formas de sujeição. Foucault (1979) discute que entre esses elementos, discursivos ou não, existe um tipo de jogo, ou seja, mudanças de posição, modificações de funções, certa manipulação das relações de força que de forma racional utiliza, bloqueia, estabiliza, faz seguir certas direções, numa função estratégica dominante.

Segundo Foucault (1987), além do dispositivo ter uma função estratégica, estaria enunciando uma nova concepção política do poder em oposição a qualquer teoria de Estado, pois não atua por repressão ou ideologia e seus movimentos

\footnotetext{
${ }^{3}$ Panóptico é um termo utilizado para designar um centro penitenciário ideal desenhado pelo filósofo Jeremy Bentham em 1791. O conceito do desenho permite a um vigilante observar todos os prisioneiros sem que estes possam saber se estão ou não sendo observados. Através de um efeito de visibilidade constante, impessoal e automático, faz com que o prisioneiro, mesmo sem a presença dos vigias, se sinta visto. Esse dispositivo de poder se multiplicou e se desdobrou em outros mecanismos. A lógica aqui é, portanto, a da contaminação: do hospício à escola, uma multiplicidade de dispositivos que se criam, se transformam e se articulam de forma reticular (FOUCAULT, 1987).

${ }^{4}$ Agamben (2006) descreve que "[...] não somente, portanto, as prisões, os manicômios, o Panóptico, as escolas, as confissões, as fábricas, as disciplinas, as medidas jurídicas etc, cuja conexão com o poder é em certo sentido evidente, mas também a caneta, a escritura, a literatura, a filosofia, a agricultura, o cigarro, a navegação, os computadores, os telefones celulares e - porque não - a linguagem mesma, que é talvez o mais antigo dos dispositivos, em que há milhares e milhares de anos um primata - provavelmente sem dar-se conta das consequências que se seguiriam - teve a inconsciência de se deixar capturar" (p.13).
}

Cad. de Pesq. Interdisc. em Ci-s. Hum-s., Florianópolis, v.11, n.99, p. 72-92, jul/dez. 2010 
históricos são possíveis de visualizar a partir da genealogia. Foucault (1994a) elucida que o dispositivo define o nexo do jogo que pode existir entre elementos como discursos científicos, filosóficos e morais, instituições, leis, arquiteturas, medidas administrativas, superando a dualidade entre formações discursivas (saber) e não-discursivas (poder). Deleuze (1990) expõe, nesses termos, que as dimensões de um dispositivo são as "curvas de enunciação e as curvas de visibilidade", ou "máquinas de fazer falar e de fazer ver". Os dispositivos são processos singulares, operam distintamente e de forma específica em relação a outros dispositivos, não têm coordenadas constantes.

Dreyfus \& Rabinow (1995) destacam que a tradução de dispositivo para o inglês foi a palavra "aparelho", podendo aproximar da expressão "rede de inteligibilidade", que reúne poder e saber numa rede específica de análise, num conjunto de práticas coerentes que organizam a conjuntura social. Para Agamben (2005) o sentido da palavra dispositivo, tanto no uso comum ou foucaultiano, "[...] parece referir a la disposición de una serie de prácticas y de mecanismos (conjuntamente lingüísticos y no lingüísticos, jurídicos, técnicos y militares) con el objetivo de hacer frente a una urgencia y de conseguir un efecto" (p. 3).

Problematizamos uma questão estratégica para entender o processo que envolve, por exemplo, as tecnologias de governo. Se focarmos as técnicas de gestão governamental, desde o cálculo das estatísticas e a ação gestora da Polícia no século XVIII até os dispositivos tecnológicos informacionais do século $X X$, é possível perceber que ambos agregam uma rede de mecanismos finos, sutis, emergentes sob um discurso inovador e progressista, construídos por uma história de práticas que remontam o controle de fluxos das populações e recobrem tipos específicos de poder político. As recentes geotecnologias, que diagnosticam tanto o território quanto a população, com buscas personalizadas, informações muito íntimas e um mapeamento interpolado que conecta cada pessoa e cada deslocamento dela no uso dos espaços, formaram uma rede de práticas de vigilância e exame, de regulação social, de monitoramento eletrônico, que causaram uma alavancagem na capacidade de governar pessoas através do uso calculado de políticas públicas nos último século no Ocidente. 
Em nossa dissertação de mestrado, mostramos como a geotecnologia "geoprocessamento" utilizada como técnica de governo é o dispositivo tecnológico específico de função biopolítica que engloba num mesmo mecanismo essa possibilidade de uma análise enquanto prática de poder, instrumento de produção de informações (discursos) e possível meio de as pessoas produzirem uma relação consigo mesmo de vigilância e sujeição a uma forma de poder fina e sutil. Ele possui peculiaridades para gerar problematizações, tal como um suporte de saber muito grande e sofisticado, e o desenho de uma tensão que gera um dispositivo onde essas informações podem ser cruzadas ou usadas politicamente no governo das populações e da vida dos indivíduos. Um estratagema de uma rede de poder e regulação que cresce na velocidade das descobertas da ciência.

\subsection{Dispositivo como método e como objeto}

Para você, qual é o sentido e a função metodológica deste termo: dispositivo? M.F.: Através deste termo tento demarcar, em primeiro lugar, um conjunto decididamente heterogêneo que engloba discursos, instituições, organizações arquitetônicas, decisões regulamentares, leis, medidas administrativas, enunciados científicos, proposições filosóficas, morais, filantrópicas. Em suma, o dito e o não dito são os elementos do dispositivo. O dispositivo é a rede que se pode estabelecer entre estes elementos (FOUCAULT, 1979, p. 244).

Caso pudéssemos arriscar que essa tecnologia de governo seja diferente das já estudadas por Michel Foucault, e ao risco de remontar peças que já existiam de outros quebra-cabeças do pensador, buscamos analisar uma forma de investigação forjada pelo próprio objeto de pesquisa e pela aproximação de um método que fizesse sentido com a trajetória dos objetos já pesquisados por ele. Se entendermos o método como o caminho a ser percorrido ao alcance do objeto pesquisado, poderíamos dizer que o "dispositivo" é o mapa desse caminho, mas também, o próprio ponto de chegada.

Essa é uma afirmação complexa de se fazer, pois não existe um método fechado e generalizável para Foucault. Só a partir dos seus interlocutores: Deleuze, Dreyfus e Rabinow e Agamben, e nos seus últimos ditos e escritos, é possível

\footnotetext{
${ }^{5}$ Geoprocessamento, de acordo com Rodrigues (1988) é uma tecnologia de coleta e tratamento de informações espaciais e de desenvolvimento de sistemas que as utilizam. É a conjugação da nova forma de geração dos documentos cartográficos com a metodologia de análise espacial transposta para o computador. A partir dessa ideia se desenvolveu uma ferramenta específica, o Sistema de Informação Geográfica (SIG). O SIG se baseia exatamente em imagens aéreas (satélites ou foto aérea), vinculado a um banco de dados, cruzando as duas informações para expor determinada situação com uma visão geral ou específica para um sistema de gestão organizacional.
}

Cad. de Pesq. Interdisc. em Ci-s. Hum-s., Florianópolis, v.11, n.99, p. 72-92, jul/dez. 2010 
considerar que o dispositivo é um conceito central em seu pensamento. Seria difícil dizer que o dispositivo seria o conceito resumo de seu pensamento, porém os conceitos usados como: máquina, aparelho, sistema, técnica ou tecnologia (em seu sentido lato), por meio dele tiveram uma construção conceitual aprimorada, um vetor que localiza e gera inteligibilidade para os objetos a ser investigados.

Quando falamos em utilizar o "dispositivo" como "método e objeto" de pesquisa e enfrentamos esse vazio metodológico-conceitual evidente, de uma nova flexão dos modos de pesquisar em Foucault, precisamos dar suporte a esse caminho. Para tanto, se o dispositivo é o vetor e tensor na rede que se estabelece entre os elementos de análise de uma pesquisa, usamos a arqueologia do saber, genealogia do poder e genealogia da ética como base para investigação, visto que foram elas as utilizadas para analisar, por exemplo, o dispositivo do Panóptico no livro "Vigiar e Punir", o dispositivo da Sexualidade no livro "História da Sexualidade: Vontade de Saber" e o dispositivo de Segurança no livro "Segurança, Território e População".

Para Foucault (1979) o dispositivo possui uma formação histórica, tem uma função estratégica e está sempre disposto em um jogo de poder ligado a configurações de saber e subjetividade. O discurso pode aparecer como programa de uma instituição, ou como lei justificando a implantação de um dispositivo, ou, ao contrário, como elemento que permite justificar e mascarar estas práticas que permanecem mudas. Existem algumas possibilidades de exploração do dispositivo, pois "a forma de pesquisar se constrói em função da especificidade de cada objeto".

A forma de investigação utilizada neste contexto, em relação aos dispositivos de poder, verdade, sexualidade, segurança e loucura, permite esboçar uma estratégia de pesquisa inicial, uma construção da forma de acesso e possível análise das informações.

\footnotetext{
O dispositivo, portanto, está sempre inscrito em um jogo de poder, estando sempre, no entanto, ligado a uma ou a configurações de saber que dele nascem, mas que igualmente o condicionam. $\mathrm{E}$ isto, o dispositivo: estratégias de relações de força sustentando tipos de saber e sendo sustentadas por eles (FOUCAULT, 1979, p.246).
}

No livro "História da Sexualidade: O Uso dos Prazeres", o projeto de investigação que trata a história da sexualidade enquanto correlação, numa cultura, entre campos de saber, tipos de normatividade e formas de subjetividade, demonstra um Foucault (1984) que consegue olhar para a conjuntura de sua Cad. de Pesq. Interdisc. em Ci-s. Hum-s., Florianópolis, v.11, n.99, p. 72-92, jul/dez. 2010 
produção textual e vincular ao dispositivo três eixos de análise. Falamos do dispositivo da sexualidade que é constituído pela:

[...] formação dos saberes que a ela se referem, os sistemas de poder que regulam sua prática e as formas pelas quais os indivíduos podem e devem se reconhecer como sujeitos dessa sexualidade. Ora, sobre os dois primeiros pontos o trabalho que empreendi anteriormente - seja a propósito da medicina e da psiquiatria, seja a propósito do poder punitivo e das práticas disciplinares - deu-me os instrumentos dos quais necessitava; a análise das práticas discursivas permitia seguir a formação dos saberes, escapando ao dilema entre ciência e ideologia; a análise das relações de poder e de suas tecnologias permitia focalizá-las como estratégias abertas, escapando à alternativa entre um poder concebido como dominação ou denunciado como simulacro (p. 10).

Descrito por Deleuze (1990), é possível utilizar os termos "vetor ou tensor" para representar a conexão que existe entre esses objetos visíveis, enunciações formuláveis, forças em exercício e sujeitos numa determinada posição. "Dessa maneira, as três grandes instâncias que Foucault distingue sucessivamente (Saber, Poder, Subjetividade) não possuem, de modo definitivo, contornos definitivos; são antes cadeias de variáveis relacionadas entre si” (p.155). Sobre essas três análises, ainda Foucault, numa entrevista para Dreyfus \& Rabinow (1995), responde que existem:

Três domínios de genealogia são possíveis. Primeiro, uma ontologia histórica de nós mesmo em relação à verdade através da qual nos constituímos como sujeitos de saber; segundo, uma ontologia histórica de nós mesmos em relação a um campo de poder através do qual nos constituímos sujeitos de ação sobre os outros; terceiro, uma ontologia histórica em relação à ética através da qual nos constituímos como agente morais. O eixo da verdade foi estudado em Nascimento da Clínica e As Palavras e as Coisas. O eixo do poder foi estudado em Vigiar e Punir, e o eixo ético em História da Sexualidade (p. 262).

Para quem quer realizar uma pesquisa por essa perspectiva, começa a perceber os recortes que precisam ser feitos e costurados para ter uma organização inteligível do seu objeto. Descrever sumariamente o que é um dispositivo e como ele foi trabalhado em cada uma das pesquisas dos anos 60, 70 e 80 de Foucault pode ser perda de tempo. O ponto em comum que favorece o entendimento enquanto método desse processo e o caminho que tem mais consenso entre os estudiosos de Foucault são as articulações que a arqueologia e genealogia geram, para suportar os eixos de um dispositivo. 


\subsection{Contribuições da arqueologia e genealogia para constituição do dispositivo}

Usamos essas duas engrenagens sob um desafio de construir procedimentos de pesquisa com a "caixa de ferramentas" que Foucault (2006) nos oferece, compreendendo que não se trata aqui de uma metodologia, um campo sistemático, um roteiro pré-estabelecido, a não ser um instrumento, uma lógica própria de olhar as relações de poder e as lutas que se engajam em torno delas. Inegavelmente estamos dentro de uma reflexão sobre um tipo de história específica sobre situações dadas.

\footnotetext{
A arqueologia do saber não é um livro de metodologia. Não tenho um método que aplicaria, do mesmo modo, a domínios diferentes. Ao contrário, diria que é um mesmo campo de objetos, um domínio de objetos que procuro isolar, utilizando instrumentos encontrados ou forjados por mim, no exato momento em que faço minha pesquisa, mas sem privilegiar de modo algum o problema do método (FOUCAULT, 2006, p.229).
}

Na entrevista chamada "A Poeira e a Nuvem" Foucault (2006), em resposta as críticas de J. Léonard, oferece ferramentas e alguns cuidados "metodológicos", debatendo que não basta para uma pesquisa somente delimitar o objeto, o tempo que se situará e os limites de abrangência da análise, seria mais razoável perguntar: Quais os documentos necessários para fazer aparecer a racionalidade do objeto que se subscreve? Onde no tempo interessa a análise, nos acontecimentos precedentes de sua emergência ou nos que se segue? Tiveram esses acontecimentos posteriores que efeitos na organização, nas regras e no dispositivo analisado? Foucault (2006) delimita que é preciso: fazer um tratamento exaustivo de todo material; repartição cronológica do exame; escolha do material em função dos dados do problema; focalização da análise sobre elementos suscetíveis de resolvê-lo; estabelecimento das relações que permitem essa solução; fixar os pontos de ancoragem de uma estratégia; determinar por que tal estratégia e tais instrumentos táticos foram escolhidos em função de outros. "E, portanto, indiferença para com a obrigação de tudo dizer, mesmo para satisfazer o júri dos especialistas convocados" (p. 326-328).

As direções de pesquisa apontadas pela arqueologia do saber e pela genealogia do poder se constituem como dois conjuntos complementares, sendo sua diferença não tanto de objeto ou de domínio, mas de ponto de ataque, de perspectiva e de delimitação. Segundo Fae (2005), a arqueologia tem por propósito 
descrever a constituição do campo, entendendo-o como uma rede, formada na interrelação dos diversos saberes ali presentes. E é exatamente nesta rede, pelas características que lhe são próprias, que se abre o espaço de possibilidade para a emergência do discurso. Já a genealogia considera a configuração desses saberes e discursos como elementos de um dispositivo de natureza essencialmente estratégica. Procura-se a explicação dos fatores que interferem na sua emergência, permanência e adequação ao campo discursivo, defendendo sua existência como elementos incluídos em um dispositivo político. Assim, a genealogia é um método que visa analisar o poder em seu contexto prático, ligado às condições que permitiram sua emergência, fazendo a análise histórica das condições políticas de possibilidade dos discursos; desta forma, o genealogista não busca a origem, mas a proveniência.

Foucault (2006) declara que buscava as relações que existem entre o poder e saber, analisando o saber em termos de região, de domínio, de implantação, de deslocamento, de transferência, apreendidos no processo pelo qual o saber funciona como um poder e reconduz seus efeitos. Para Foucault (1985) um caminho possível se dispõe ao nível de sua produtividade tática, buscando que efeitos recíprocos existem entre poder e saber, e de sua integração estratégica, interrogando "[...] que conjuntura e que correlação de forças torna necessária sua utilização em tal ou qual episódio dos diversos confrontos produzidos" (p. 97).

Dreyfus e Rabinow (1995) afirmam que essa constatação referente a engendrar nos pólos do saber e poder é advinda do abandono da arqueologia como método único, que servia para isolar discursos-objetos. Segundo estes autores, Foucault percebe que sem a genealogia e a arqueologia para articular as relações entre o discurso, a verdade, o poder, as instituições e valores, não têm como ver o tipo de influência das instituições e permitir que surjam críticas do autor frente às preocupações sociais, tanto quanto diagnosticar como esses discursos são utilizados. Dreyfus e Rabinow ainda dizem que para o arqueólogo a tarefa é descrever em termos teóricos as regras que regem as práticas discursivas e 0 genealogista diagnosticar e compreender a racionalidade das práticas sociais de poder; que nos subjetivaram pelos seus efeitos e nos objetivaram pela suas tecnologias. Deleuze (1991) pronuncia que existe uma mistura indissociável das práticas discursivas de enunciados (práticas de dizer, arquivo, palavra, regras, 
programas) e práticas não-discursivas de visibilidades (práticas de ver, diagrama, arquitetura, aparelhos, mecanismos) que só existem numa multiplicidade de forças.

Para Prado Filho (2006) a arqueologia do saber se ocupa dos regimes de produção dos discursos, dos jogos de produção de verdades e das práticas discursivas de uma sociedade. Esse caminho constitui elementos fundamentais para forjar procedimentos para o objeto específico, como uma tecnologia de governo. Falamos em uma análise de discurso que engloba o momento que surge, acontece, forma matrizes em jogo, com enunciados localizados em um tempo, cultura e condições de possibilidades. Foucault (1972) ao invés de analisar o saber na direção das ideias persegue-o na direção das lutas, dos conflitos, das decisões e das táticas. Onde dentro da sociedade estão constituídos os regimes, regras, estatutos e convenções que estabelecem, julgam ou produzem efeito (impressão) do que é verdadeiro ou falso. Foucault (1994a) expõe que:

\begin{abstract}
Meu problema é saber como os homens se governam (a si mesmos e os outros) através da produção da verdade (o repito uma vez mais, por produção da verdade não entendo a produção de enunciados verdadeiros, sem o ajuste de domínios onde a prática do verdadeiro e o falso pode ser, a esta vez, regrada e pertinente). Acontencimentalizar os conjuntos singulares de práticas para fazê-los aparecer como regimes diferentes de jurisdição e verificação. [...] Eu quis, em definitivo, problematizar o regimento da produção do verdadeiro e do falso no coração da análise histórica e da crítica política (p. 27).
\end{abstract}

Foucault (1979) cita que, seja o jogo centrado nos vários formatos de discurso científico ou nas instituições que a produzem esses critérios de verdade, sancionadas ou não por mecanismos (práticas discursivas e não-discursivas), e instâncias constituídas por métodos e técnicas, ambos estão submetidos a uma constante incitação econômica e política.

Conforme Foucault (1972), nesse tipo de pesquisa, não são analisadas unidades linguísticas, frases, preposições, estruturas, significados, sentidos, semântica, mas sim as práticas, enunciados e produções de verdades dentro da trama das relações de poder. A arqueologia é um empreendimento puramente descritivo dos acontecimentos discursivos, e são eles que produzem o objeto sobre o qual falam. Foucault (1987) pronuncia que além de descrever enunciados são analisados as condições nas quais esta função se exerce, os diferentes domínios que ela supõe e a maneira pela qual eles se articulam. Foucault (1972) escreve que a análise de um campo discursivo advém ao compreender o enunciado na estreiteza 
e singularidade de seu acontecimento. Assim, localizam-se suas condições de existência, limites e correlações com os outros enunciados e que outras formas de enunciação exclui. Para Foucault (1997) as práticas discursivas não são apenas modos de fabricação de discursos, elas "[...] ganham corpo em conjuntos técnicos, em instituições, em esquemas de comportamento, em tipos de transmissão e difusão, em formas pedagógicas, que ao mesmo tempo as impõem e as mantêm" (p.12). O acontecimento enunciativo, como estipula Foucault (1972), não está relacionado com intenções puramente psicológicas de um autor, rigor de um pensamento ou dos temas e projetos que atravessam a existência e a significação, porém, é possível apreendê-lo sob suas formas de regularidade e tipos de relações:

Relações dos enunciados entre si (mesmo que escapem à consciência do
autor; mesmo que se trate de enunciados que não têm o mesmo autor;
mesmo que os autores entre si não se conheçam); relações entre grupos de
enunciados assim estabelecidos (mesmo que esses grupos não se remetam
aos mesmos domínios ou a domínios vizinhos; mesmo que não tenham o
mesmo nível formal; mesmo que não sejam lugar de trocas determinadas);
relações entre enunciados e grupos de enunciados e acontecimentos de
uma ordem inteiramente diferente (técnica, econômica, social e política).
Fazer aparecer em sua pureza o espaço em que se desenvolvem os
acontecimentos discursivos não é tentar restabelecê-lo em um isolamento
que nada poderia superar; não é fechá-lo em si mesmo; é tornar-se livre
para descrever nele e fora dele jogos de relações (p.41).

Spink (1999) explora que os documentos são tão "presentes" quanto uma entrevista ou discussão de grupo. "Nenhum é mais representativo do que o outro, todos - por existirem num determinado momento - têm uma presença, tornando redundante a própria noção da representatividade" (p.125). Nessa discussão, é importante discutir que, para Foucault (2006) não é a entrevista que vai trazer a verdade sobre o que está acontecendo, pois diferentemente dos "monumentos" escritos teríamos acesso a "bastidores" pelo discurso das pessoas. Antes disso, ele pergunta o que é essa relação entre "verdade e realidade", senão fazer aparecer os discursos em suas conexões estratégicas em relação aos jogos de poder. O discurso emergindo no próprio movimento histórico que o constitui expressão de uma prática de governo.

Foucault (1995) nos traz mais algumas precauções ao problematizar o que é e como funciona o poder. O autor estipula algumas direções de como analisá-lo, pois além de percorrê-lo desde as extremidades e possibilitar um ponto de vista positivo sobre o poder, devemos considerar: a) quais sistemas de diferenciação 
permitem que uns atuem sobre os outros (diferenças jurídicas, tradicionais, econômicas, competências cognitivas, etc.); b) quais objetivos perseguem (conservar privilégios, acumular riquezas, exercer uma profissão); c) quais modalidades instrumentais se utilizam (as palavras, o dinheiro, a vigilância, os registros); d) quais formas de institucionalização estão implicadas (os costumes, as estruturas jurídicas, os regulamentos, as hierarquias, a burocracia); e) que tipo de racionalidade está em jogo (tecnológica, econômica).

A genealogia de Foucault, segundo Pogrebinschi (2004), é também baseada em alguns pontos, como: a exterioridade, onde existe a busca do ponto exato onde o poder se estabelece e produz seus efeitos; a localidade, sendo o poder analisado em suas formas e em suas instituições mais locais, afastando de um suposto centro do poder, aproximando das micro-físicas e mecanismos específicos; a circularidade, entendendo que o poder não é fixo as mãos e ao domínio de alguém, é algo que circula incessantemente nas relações dos indivíduos, acabando que todos são detentores e destinatários do poder, seus sujeitos ativos e passivos; a ascensão, rejeitando uma análise que parta do alto (do dito soberano) para baixo (sujeitados), mas de baixo para cima, pesquisando as "formas de sujeição", analisando como a cada passo essa relação de poder foi se constituindo; não-ideologização, analisando que o que está na base do poder não são as ideologias, mas os instrumentos de formação e acúmulo de saber que movimentam um dispositivo de poder.

A genealogia do poder feita no livro "Vigiar e Punir" de Foucault (1987), principalmente no ponto que se refere ao panóptico, para além de um projeto arquitetônico da tecnologia de vigilância e disciplinação de corpos surgido na Europa no século XVII, nos oferece um exemplo de abordagem histórica de um dispositivo de poder. Temos a combinação de um mecanismo e várias práticas disciplinares que tornaram o exercício de poder mais rápido, leve e eficaz, num desenho de coerções sutis que movimentaram toda uma sociedade com tal consequência para a chamada "vigilância integral", que pôde ser comparada como a máquina a vapor foi na ordem da produção industrial. Outro tipo de dispositivo analisado foi o da sexualidade, que de acordo com Foucault (1985), é um tipo de poder que captura os corpos, sua materialidade, suas forças, suas energias, sensações, e prazeres entre quatro estratégias globais de dominação: a histerização do corpo da mulher, a pedagogização do corpo da criança, a socialização das condutas de procriação e a 
psiquiatrização do prazer "perverso", que emergem no século XVIII criando uma relação entre degenerescência, hereditariedade e perversão.

A emergência desses dispositivos na ordem do poder, saber e subjetividade nos oferecem referências importantes de como podemos basear alguns procedimentos de análise. Porém, é importante prestar atenção, pois existe o envolvimento de um objeto específico que se flexiona a um método também particular. São diversas práticas e condições de possibilidades próprias da sociedade ocidental nas últimas décadas que remontam tecnologias para além da disciplinar. Situamos aqui a biopolítica, o biopoder e as tecnologias que tem em seus rastros e peças, partes das práticas disciplinares, mas que empreenderam novas formas de intervenção social.

Outro ponto específico que Foucault (1995) nos adverte é que ao estudar relações de poder não podemos reduzi-las ao estudo de instituições conhecidas como "políticas". Mesmo analisando técnicas de gestão de populações, dispositivos biopolíticos dentro de uma tecnologia política, tais relações dentro da instituição política estão enraizadas em redes sociais e práticas cotidianas que produzem enunciados e estão sob formas de governo constituídas por um dispositivo próprio, e constitui uma análise possível de poder-saber das práticas que o constituem como tal.

\section{DISCURSO DOS DISPOSITIVOS TECNOLÓGICOS DE GOVERNO}

Para analisar a emergência de um dispositivo é necessário explicar que o tipo de análise histórica que Foucault (1972) fez é diferente das demais formas tradicionais, pelo cálculo exato e linearidade do passado, atribuídos aos historiadores das ciências. Se o dispositivo surge, inicialmente não tratamos de uma origem ideal, primeira, especialmente localizada, mas sim um conjunto de recobrimentos e camadas dos fatos sobre o tempo e seu registro dentro dessa dispersão temporal. As recentes tecnologias de governo não tiveram sua geração espontânea no advento das tecnologias da informação e governo eletrônico das últimas décadas, nem do uso da estatística pela garantia da soberania dos governos durante o século XVIII ou com o desenvolvimento da ciência política, nem mesmo do uso estratégico do mapeamento feito nas antigas batalhas do oriente e do ocidente 
antigo. Esses dispositivos, antes de ter seu uso estratégico, foi sendo constituído por tecnologias e práticas políticas que foram se agregando pela história de forma plástica pela irrupção de acontecimentos e técnicas governamentais e, da mesma maneira, poderá continuar sua performance pelos anos a seguir de acordo com seus meios de construção.

Pela emergência destes dispositivos não ter marcos cronológicos, podemos problematizá-lo enquanto história do presente, olhando para a história como uma forma de compreender os processos que levaram ao que existe e somos hoje. Nesse sentido, podem-se apontar as condições de possibilidade e visibilidade que permitiu a ruptura e recobrimento, por exemplo, das geotecnologias (citando aqui o geoprocessamento) sobre outros dispositivos e tecnologias, e buscar respostas as perguntas: Em quais condições foi possível vê-lo e fazê-lo aparecer, ser possível que ele exista e seja aprovado, ou mesmo, em que meios, em que instâncias, em que jogos de saber-poder ele virou um acontecimento até ser aplicado?

Para Foucault (1972) o sistema que rege o aparecimento e a funcionalidade de um enunciado é descrito pelo arquivo. E a sua descrição chama-se arqueologia. "São todos esses sistemas de enunciados (acontecimentos de um lado, coisas de outro) que proponho chamar de arquivo" (p.160). O que significa que a emergência dos discursos sobre novas tecnologias de governo mesmo em cidades ou locais mais isolados, onde não foram implantadas tecnologias de última geração, mas como nas que já existe, deu-se por um discurso manifesto que se encontra repousado secretamente por um já-dito, por meios de inserção na população já realizados, que garantem sua aprovação e continuidade fluida pelas populações. Porém temos o agrupamento de coisas ditas em figuras distintas, composições diversas estabelecidas segundo uma multiplicidade de relações resultando num acontecimento singular, uma irrupção neste tempo/espaço. O dispositivo (objeto), os discursos que ganham visibilidade, sua emergência dentro de relações de enfrentamento aparecem num contexto específico. E é esse arquivo de fatos e produções discursivas neste contexto que faz com que as coisas ditas se mantenham, que faz aparecer as regras que organizam essa prática discursiva num corpo enunciativo que buscamos desenhar.

Segundo Foucault (2006), a possibilidade de descrever essas práticas se transmite através dos discursos dos documentos necessários para fazer aparecer a racionalidade do objeto em questão. $O$ tempo de análise que se subscreve se

Cad. de Pesq. Interdisc. em Ci-s. Hum-s., Florianópolis, v.11, n.99, p. 72-92, jul/dez. 2010 
focalizará nos acontecimentos precedentes de sua emergência, de acordo com a direção dos dados conseguidos no momento da pesquisa. E é descobrir como essa emergência de discursos e práticas acontece que nos gera um desafio para cada objeto. Se existe um conjunto de fatores de sedução, fetiche ou desejo que faz os sujeitos buscarem as novas tecnologias, tem em seu contraponto a necessidade de saber como esses mesmos sujeitos aceitam, resistem ou rejeitam as inovações dos dispositivos sob o discurso do progresso.

\section{A SUBJETIVIDADE E A RESISTÊNCIA AOS DISPOSITIVOS}

Os computadores se transformarão tão pequenos que serão invisíveis. Vão estar entre todas as partes e ao mesmo tempo nenhuma, e serão tão poderosos que vão desaparecer da vista. Pensamos nos carros mais modernos, equipados com dispositivos silenciosos acionados por pequenos computadores de que não somos conscientes (levanta vidros, calefação, etc.). [...] Longe de ser um problema futuro, essa invisibilidade já está entre nós (DELEUZE apud GIORGI \& RODRÍGUEZ, 2007, p.164).

As práticas exercidas por agressividade, segundo Foucault (1995), não são formas de poder, mas sim de violência ${ }^{6}$. O poder está numa estrutura de ações que induz, incita, seduz, facilita ou dificulta e ao extremo constrange, pois é sempre um conjunto de ações sobre outras ações. Segundo Stassun (2009), esse poder sutil é tão fino que no caso de dispositivos de vigilância, a invasão de privacidade tão cotidiana faz muitas vezes com que o próprio sujeito peça para ser vigiado, ser policiado e ser percebido. Quanto mais as práticas de poder chamam atenção, ameaçam, reprimem mais elas causam resistência. Porém, o que é problematizado, é justamente a ambiguidade que permeia a discussão desse exemplo específico, as câmeras de vigilância. Pois a mesma tecnologia que monitora a performance e os comportamentos dos sujeitos, pode aumentar a segurança no espaços de circulação e gerar informações úteis de trânsito, acidentes e problemas nas vias. A sensação de segurança e medo, de autonomia e de gerência das atitudes são exemplos dos efeitos duais de dispositivos de segurança na sociedade atual.

\footnotetext{
6 "Se um dos dois estiver completamente à disposição do outro e se tornar sua coisa, um objeto sobre o qual se pode exercer uma violência infinita e ilimitada, aí não haveria relações de poder. É preciso então para se exercer uma relação de poder, que exista sempre dos dois lados uma certa forma de liberdade... Isto quer dizer que nas relações de poder existe forçosamente possibilidade de resistência, pois se não houvesse possibilidade de resistência - de resistência violenta, de fuga, de ardil, de estratégias que invertam a situação - não existiria relações de poder" (FOUCAULT, 1994a, p. 720).
}

Cad. de Pesq. Interdisc. em Ci-s. Hum-s., Florianópolis, v.11, n.99, p. 72-92, jul/dez. 2010 
Como se pode resistir ao poder, se a resistência só existe dentro dessas relações ${ }^{7}$ Foucault (2006) aponta que do "exterior" se pode causar suas próprias revoluções por meio de uma técnica de demolição crítica, que nos permite contestar os sistemas que se ordenam por toda cortina que veste a sociedade. "É preciso pôr 'em cena', exibir, transformar e derrubar os sistemas que nos ordenam pacificamente. Quanto a mim, é o que tento fazer no meu trabalho" (p. 25). Pode-se agir e resistir aos discursos emergentes das práticas de poder, sabendo quais as condições de possibilidade permitiu que esses discursos tomassem forma concreta através das tecnologias de governo, fazendo aparecer esses discursos em suas conexões estratégicas e extraindo acontecimentos discursivos de dentro de um arquivo, suas técnicas e modelos de emergência.

\begin{abstract}
Há terror quando mesmo aqueles que comandam tremem, porque sabem que de qualquer modo o sistema geral da obediência os envolve tanto quanto àqueles sobre os quais exerce seu poder (Foucault, 2008, p. 265). [...] o terror no fundo, não é o auge da disciplina, é o seu fracasso. No regime stalinista, o próprio chefe de polícia podia ser executado num belo dia, ao sair da reunião do ministério. Nenhum chefe da NKVD morreu na cama (Notas 28, in FOUCAULT, 2008, p. 294).
\end{abstract}

Quando Foucault (2008) descreveu que o que se governa são as pessoas, os indivíduos, as coletividades e as condições de sobrevivência dentro de um território, ele se referiu de forma concreta, sobre o governo das ações, das atitudes, dos comportamentos e das condutas que guiam essas pessoas. "Possibilidade de ação sobre a ação dos outros" (FOUCAULT, 1995, p.247). Imaginem construir um labirinto por onde as populações só poderão circular em espaço determinado, "as pessoas escolhem", mas somente no espaço pré-estabelecido. As biopolíticas ${ }^{8}$, como outro exemplo, tendo uma base científica de informações gerada por tecnologias de governo (geoprocessamento) para serem aplicadas as populações, podem ter

7 Foucault (1999) aponta como critério de pesquisa, "[...] não perguntar aos sujeitos como, por que, em nome de que direito eles podem aceitar deixar-se sujeitar, mas mostrar como são as relações de sujeição efetivas que fabricam sujeitos" (p. 51). E para tanto, descrever parte das práticas dos dispositivos em questão, é fazer a leitura dos operadores de sujeição. "[...] Eu não quero dizer, é claro, que não há, ou que não se pode atingir nem descrever os grandes aparelhos de poder. Mas eu creio que estes funcionam sempre sobre a base desses dispositivos de dominação" (FOUCAULT, 1999, p.51).

${ }^{8}$ Foucault (1997) escreve que: "A biopolítica tende a tratar a população como um conjunto de seres vivos e coexistentes, que apresentem traços biológicos e patológicos particulares, e que, por conseguinte, dizem respeito a técnicas e saberes específicos. E a própria biopolítica deve ser compreendida a partir de um tema desenvolvido desde o século XVII: a gestão das forças estatais" (p. 86). A biopolítica é a forma de governar final da aplicação de práticas sociais de poder e saber, podendo ser visualizadas historicamente por Foucault (2008), como a maneira de conduzir, dirigir, sustentar e conhecer as particularidades da população.

Cad. de Pesq. Interdisc. em Ci-s. Hum-s., Florianópolis, v.11, n.99, p. 72-92, jul/dez. 2010 
autorização e autoridade para construir esse labirinto por onde se dá o fluxo cotidiano. Um gestor permeando suas ações pelas vias que as ações biopolíticas traçaram e ainda podendo vigiar todo processo 24 horas por dia por sistemas de monitoramento e mapear todo um campo de investimentos políticos por fotos de satélite muito detalhadas. Cada pessoa circulando sobre os caminhos pré-traçados pelas políticas públicas, e sempre tendo a sensação de liberdade, pelos sutis elementos ausentes, a coação ou a violência. Nas relações de poder "[...] há uma 'insubmissão' e liberdades essencialmente renitentes, não há relação de poder sem resistência, sem escapatória ou fuga, sem inversão eventual. [Porém] a liberdade aparecerá como condição da existência do poder" (FOUCAULT, 1995, p.244). O ato de "conduzir", é menos um afrontamento de adversários do que da ordem do governo, é a maneira de se comportar num campo mais ou menos aberto de possibilidades, onde o poder aparece conduzindo as condutas num espaço que o sujeito precisa se sentir livre, liberto; lugar esse, onde as práticas o capturem e façam com que o sujeito tenha uma resistência não maior do que a constância das práticas do dispositivo. Essa forma de análise seria uma especulação? Teoria de conspiração? Ou uma visão específica de realidade?

Foucault (1995) fala que o foco do trabalho dele foi estudar o modo pelo qual um ser humano se torna sujeito, e forma pelo qual ele é sujeitado por um conjunto de práticas sociais que fazem parte da sua constituição, seja por situações cotidianas, onde são assujeitados pela norma (ética), atravessados pelas práticas de poder e inseridos num regime discursivo. "O 'sujeito' já não designa simplesmente o indivíduo sujeitado, mas a singularidade que se afirma na resistência ao poder - as 'revoltas de conduta' ou 'contra-condutas'” (SENELLART apud FOUCAULT, 2008, p. 511). Essa contra-conduta que resiste a invasão de um dispositivo como esse, sem limites, sem restrições de intimidade e privacidade, afirma lutas contra as formas de sujeição e contra a submissão da subjetividade, que se dá de acordo com Prado Filho (1998): pelas possibilidades de fuga que permitem a resistência aos balizamentos e agenciamentos do poder; a transgressão as regras de discurso e seus efeitos de enunciação; e a partir das práticas de liberdade, crítica e sua verificação constante dessas relações. Foucault (2008) esclarece que essas formas de dissidência, revolta/recusa/contra-conduta, que objetivam reconhecer os modos de subjetivação a qual os jogos políticos nos inserem, estão presentes por toda história desde no formato de: sociedades secretas, religiões, partidos políticos, Cad. de Pesq. Interdisc. em Ci-s. Hum-s., Florianópolis, v.11, n.99, p. 72-92, jul/dez. 2010 
grupos armados ou mesmo no exercício de si sobre si contra o olhar, a ética e a autoridade do outro.

A articulação da resistência em relação ao poder não se exerce somente na "[...] maneira de dirigir a conduta dos indivíduos ou dos grupos, governo das crianças, das almas, das comunidades, das famílias, dos doentes" (FOUCAULT, 1995, p.244). O dispositivo não está num confronto de pessoas que tem no seu momento final uma vitória de um dos dois adversários, mas sim num jogo de relações antagônicas substituído por um dispositivo complexo ${ }^{9}$, permanente, fluido, "[...] por mecanismos estáveis pelos quais um dentre eles pode conduzir de maneira bastante constante e com suficiente certeza a conduta dos outros" (FOUCAULT, 1995, p.248). Essa fonte das relações de poder estáveis é um jogo que exige graus de liberdade, e mesmo havendo a permanência da manobra que as instala, "[...] desde que há uma relação de poder, há uma possibilidade de resistência. Nunca somos pegos na armadilha pelo poder: sempre podemos modificar-lhe o domínio, em determinadas condições e segundo uma estratégia precisa" (FOUCAULT, 1994, p. 267). Essa conclusão marca a última proposta de Foucault (1994(a)) em relação a discussão poder-sujeito-resistência, que se concentra em uma só operação: "Chamo 'governamentalidade'10 ao encontro entre as técnicas de dominação exercidas sobre os outros e as técnicas de si” (p. 786).

A forma de intervenção biopolítica de uma tecnologia ou inovação de governo tem um nível de resistência reduzido pelos vários elementos discursivos estatísticos, científicos, sociais, políticos, econômicos (consumismo) diluídos pela própria mecânica de poder investida? As condições de possibilidade que permitiram esses discursos emergir, o legitimam e permitem todas as ações posteriores serem aplicadas de forma justificada? Elas permitem a liberdade ao sujeito de que forma? Se o dispositivo "[...] encontra uma resistência, a única escolha é tentar reduzi-la. [E

\footnotetext{
${ }^{9}$ Dentre as formas de institucionalização das relações de poder "[...] podem também formar sistemas muito complexos, dotados de aparelhos múltiplos, como no caso do Estado que tem por função constituir o invólucro geral, a instância de controle global, o princípio de regulação e, até certo ponto também, de distribuição de todas as relações de poder num conjunto social dado" (FOUCAULT, 1995, p.246).

10 "A noção de resistência permanece, em 1978, no cerne da concepção foucaultiana da política. Assim, numa série de folhetos manuscritos sobre governamentalidade, inseridos entre duas aulas do curso, ele escreve: 'A análise da governamentalidade [...] implica que 'tudo é político'. [...] A política não é nada mais, nada menos que o que nasce com a resistência à governamentalidade, a primeira sublevação, o primeiro enfrentamento'. A ideia de 'contra-conduta', segundo a expressão exposta mais adiante, representa uma etapa essencial, no pensamento de Foucault, entre a análise das técnicas de sujeição e a análise, desenvolvida a partir de 1980, das práticas de subjetivação" (Notas 5, apud FOUCAULT, 2008, p. 287).
}

Cad. de Pesq. Interdisc. em Ci-s. Hum-s., Florianópolis, v.11, n.99, p. 72-92, jul/dez. 2010 
o objetivo dele] não é uma exclusividade do uso da violência mais do que da aquisição dos consentimentos; [...] o exercício de poder pode perfeitamente suscitar tanta aceitação quanto se queira" (FOUCAULT, 1995, p.243). São essas aceitações, consentimentos, e uma resistência silenciosa que fazem do dispositivo de governo tecnológico uma prática biopolítica potente, seja ao seu caráter positivo, pois o poder é produtivo através de técnicas de individualização e de processos de totalização, ou seja, para manter atenção e contra vigilância, assim como foi feito por centenas de anos pela filosofia, que teve o papel de vigiar os excessivos poderes de racionalidade política. 


\section{REFERÊNCIAS}

AGAMBEN, G. Che cosè un dispositivo? Roma: Nottetempo, 2006.

AGAMBEN, G. O que é um dispositivo? Outra travessia, n.5, 2005.

AGAMBEN, G. O que é um dispositivo? Conferência realizada em 26 de setembro no Brasil. Rio de Janeiro, 2005a.

BENTHAM, J. O panóptico. Org. e trad. Tomaz Tadeu da Silva. Belo Horizonte: Autêntica, 2000.

DELEUZE, G. Conversações: 1972-1990. Rio de Janeiro: Ed. 34, 1992.

DELEUZE, G. Foucault. São Paulo: Brasiliense, 1991.

DELEUZE, G. Que és un dispositivo? In: Deleuze, G. Michel Foucault: filósofo. Trad. Wanderson F. do Nascimento. Barcelona: Gedisa, 1990.

DREYFUS, H., RABINOW, P. Michel Foucault: uma trajetória filosófica: para além do estruturalismo e da hermenêutica. Rio de Janeiro: Forense Universitária, 1995.

FAE, R. A. A Genealogia em Foucault. 2005. Disponível em:

www.scielo.br/pdf/pe/v9n3/v9n3a08.pdf . Acesso em 15 set. 2007.

FOUCAULT, M. Segurança, território e população. Curso no Collège de France (1977-1978). Trad. Eduardo Brandão. São Paulo: Martins Fontes, 2008.

FOUCAULT, M. Ditos e escritos IV: estratégia, poder-saber. Org. Manoel Barros da Mota. Trad. Vera Lúcia A. Ribeiro. Rio de Janeiro: Forense Universitária, 2006.

FOUCAULT, M. Em defesa da sociedade: Curso no Collège de France (19751976). Trad. Maria Ermantina Galvão. São Paulo: Martins Fontes, 1999.

FOUCAULT, M. Resumo dos cursos do Collège de France. Rio de Janeiro: Jorge Zahar, 1997.

Cad. de Pesq. Interdisc. em Ci-s. Hum-s., Florianópolis, v.11, n.99, p. 72-92, jul/dez. 2010 
FOUCAULT, M. O sujeito e o poder. In: DREYFUS, H.; RABINOW, P. Michel Foucault: uma trajetória filosófica: para além do estruturalismo e da hermenêutica. Rio de Janeiro: Forense Universitária, 1995.

FOUCAULT, M. Dits et écrits (1954-1969). Vol. 2. Paris: Gallimard, 1994.

FOUCAULT, M. Dits et écrits (1980-1988). Vol. 4. Paris: Gallimard, 1994a.

FOUCAULT, M. Vigiar e punir. (1970-1975). Petrópolis, RJ: Vozes, 1987.

FOUCAULT, M. História da sexualidade 1: vontade de saber. Trad. Maria Thereza da Costa Albuquerque. Rio de Janeiro: Graal, 1985.

FOUCAULT, M. História da sexualidade II: uso dos prazeres. Trad. Maria Thereza da Costa Albuquerque. Rio de Janeiro: Graal, 1984.

FOUCAULT, M. Microfísica do poder. Org. e trad. Roberto Machado. 17 ed. Rio de Janeiro: Graal, 1979.

FOUCAULT, M. A Arqueologia do saber. Petrópolis (RJ): Vozes, 1972.

GIORGI, G.; RODRÍGUEZ, F. (Comps). Ensayos sobre biopolítica: excesos de vida (Gilles Deleuze / Michel Foucault / Antonio Negri / Slavoj Zizek / Giorgio Agamben). Buenos Aires: Paidós, 2007.

POGREBINSCHI, T. Foucault, beyond disciplinary power and biopower.

Disponível em: www.scielo.br/scielo.php?script=scia rttext\&pid=S0102 . Acesso em 12 mai. 2007.

PRADO FILHO, K. et al. Diversidade e diálogo: reflexões sobre alguns métodos de pesquisa em psicologia. Florianópolis: [s. n.], 2007.

PRADO FILHO, K. Uma história da governamentalidade. Rio de Janeiro: Achiamé, 2006. 
PRADO FILHO, K. Trajetórias para a leitura de uma história crítica das subjetividades na produção intelectual de Michel Foucault. 1998. Tese (Doutorado) Instituto de Sociologia, Universidade de São Paulo, São Paulo, 1998.

RODRIGUES, M. Geoprocessamento. ENCONTRO NACIONAL DE ENGENHEIROS CARTÓGRAFOS, V.1, 1988, Marília/Presidente Prudente. Anais... Marília/Presidente Prudente: UNESP, 1988. p. 144-60

SPINK, P. K. Análise de documentos de domínio público. In: SPINK, M. J. (Ed.). Práticas discursivas e produção de sentidos no cotidiano. São Paulo: Cortez, 1999.

STASSUN, C. C. S. Geoprocessamento como prática biopolítica de governo municipal: desenho de um dispositivo. 2009. Dissertação (Mestrado em Psicologia) Universidade Federal de Santa Catarina, Florianópolis, 2009.

Artigo:

Recebido em: 31/08/2010

Aceito em: 18/11/2010 